Topczewska Katarzyna, Stangret Anna, Mularczyk Agata, Szczęśniak Angelika, Rogulska Karolina, Kapczuk Patrycja. Aging and old age in the opinion of high school students in Chojnice. Journal of Education, Health and Sport. 2020;10(9):25-28. eISSN 23918306. DOI http://dx.doi.org/10.12775/JEHS.2020.10.09.003

https://apcz.umk.pl/czasopisma/index.php/JEHS/article/view/JEHS.2020.10.09.003

https://zenodo.org/record/4012081

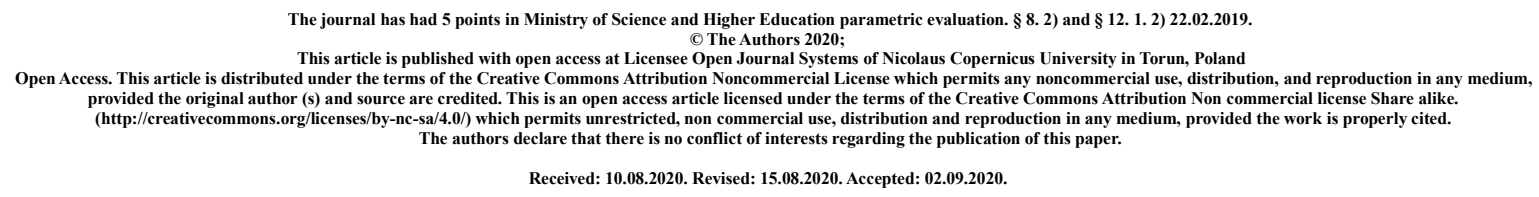

\title{
Aging and old age in the opinion of high school students in Chojnice
}

\section{Katarzyna Topczewska, Anna Stangret, Agata Mularczyk, Angelika Szczęśniak, Karolina Rogulska, Patrycja Kapczuk}

- Katarzyna Topczewska; https://orcid.org/0000-0003-2509-8289; katarzyna.topczewska@pum.edu.pl; Pomeranian Medical University, Department of Epidemiology and Management, Żołnierska Street 48, 71-210 Szczecin.

- Anna Stangret; https://orcid.org/0000-0002-2721-2121; annastangret@wp.pl; Pomeranian Medical University, Department of Human and Clinical Anatomy, Powstańców Wielkopolskich Street 72, 70-111, Szczecin.

- Agata Mularczyk; https://orcid.org/0000-0002-8273-6737; amularczyk@pum.edu.pl; Pomeranian Medical University, Department of Obstetrics and Pathology of Pregnancy, Żołnierska Street 48, 71-210, Szczecin.

- Angelika Szczęśniak; https://orcid.org/0000-0002-7854-8864; angelika.szczesniak.92@gmail.com; Pomeranian Medical University, Department of Microbiology, Immunology and Laboratory Medicine, Powstańców Wielkopolskich Street 72, 70-111, Szczecin.

- Karolina Rogulska; https://orcid.org/0000-0003-1413-7430; karolina.rogulska@pum.edu.pl; Pomeranian Medical University, Department of Microbiology, Immunology and Laboratory Medicine, Powstańców Wielkopolskich Street 72, 70-111, Szczecin.

- Patrycja Kapczuk; Pomeranian Medical University, Department of Microbiology, Immunology and Laboratory Medicine, Powstańców Wielkopolskich Street 72, 70111, Szczecin. 


\begin{abstract}
Nowadays, a significant increase in the number of post-working age people can be observed. This is due primarily to the change of life style, taking care of their own health and the development of medicine. Therefore, the perception of old people and their problems have become a common theme and subject of research. Aging and old age are referred to as the next stage in human development, which puts it in front of an extremely severe challenges or difficulties.

The aim of this study was to present the views of High School students about aging and old age. In the anonymous and voluntary survey involved 252 students in grades first Chojnice High Schools. The author's questionnaire was used, containing 26 questions. Analyzes were performed using IBM SPSS version 24 and Microsoft Office Excel.

In our own research, the relationship between the gender of respondents and the fear of old age was proved, which shows that women are more likely to fear their own old age. The correlation between place of residence and opinion on the need for elderly people in society was also examined. It was shown that among the youth living in the city up to 100,000 inhabitants were people who thought that the old people were unnecessary for the society. However, the vast majority of opinion-makers declared the need for old people in the population.

The results of the study showed that young people have a positive attitude to the older generation. There was no stereotypical perception of old people by young people.
\end{abstract}

Key words: aging, old age, youth attitudes

\title{
The process of old age and aging
}

Aging is a long-term, natural and an irreversible phenomenon that leads to old age, which is one of the stages of the human development cycle that follows maturity and ends in death [1]. Modifications occur in the human body, which over time cause its exhaustion, which may lead to numerous diseases and disability, and consequently to inevitable death $[1,2]$.

There are positive and pathological aging. A positive definition of aging is the absence of disease, and the changes in organs are relatively small. On the other hand, pathological symptoms show a deterioration of the organism's condition due to the chronic diseases [3].

From a biological perspective, aging refers to the general condition and viability of the human body. Biological aging means a gradual reduction of the functional reserve of human organs, which disturbs the maintenance of homeostasis [3,4]. This model of aging is associated with changes in human appearance, such as graying of hair, the appearance of wrinkles, change in body shape and facial features, trembling hands and a tilted body posture [5]. While biological aging is inevitable, it can be effectively slowed down. The length of an individual's life is largely determined by his genetic predisposition and the influence of stressors from the external environment [6].

\section{Intergenerational barriers and conflicts.}


The 21st century is the period of introducing new technologies. The computerization of today's world causes the disappearance of traditional interpersonal communication [7].

There are significant cultural differences between the generations, which mainly concern customs, faith and patterns behaviors and values

[8].

Looking back, it is easy to see the relationship between the young people and old people, in which the latter made key decisions regarding the social order, functioning, civilization development or socialization [9]. In the era of consumerism, the term "growing up" of young people into the adult society has become common, consisting in the feeling of equality towards the elderly and considering themselves partners in mutual relations $[8,9,10]$.

The frequency of contacts between the generations deepens the relationship between them. The causes of communication difficulties may be: old people's relations to their own lives, awareness of passing, relationships with parents, age and gender [11].

Generational differences are the consequences of the existence of diverse age groups in the same area. They can be the causes of conflicts perceived in society. Mutual relations between young people and the elderly have always been observed, which is inevitable due to the same place of existence. The course of the evolution of these interactions, caused by the changing society, in particular the change in the concept and structure of the family in which both these groups function together, may seem interesting.

\section{The main aim of the research:}

The aim of this study was to analyze the opinions of young people from Chojnice secondary schools on aging and old age.

\section{Research methods}

In order to carry out the research, the method of a diagnostic survey with the use of a questionnaire was used. The survey was conducted anonymously and voluntarily among a group of high school students in Chojnice. The questions concerned mainly views on aging and old age as well as youth attitudes towards this phenomenon.

\section{Research material}

The study involved 252 people attending all general secondary schools in Chojnice in the Pomeranian Voivodeship. All participants in the study gave their informed consent. Participation was fully anonymous and voluntary. The study was conducted from January to February 2018.

\section{Summary of research result}

- The word "old age" is most often associated with: life experience, taking care of grandchildren and free time.

- The features that, according to young people, are best reflected by older people are experience, caring and family-oriented.

- The vast majority of respondents believe that the senile age begins at the turn of 60-69 years of age.

- More than half of the respondents showed fear of old age. In the opinion of young people, 
the factors most often triggering these feelings were loneliness, death and suffering.

- The vast majority of young people feel positive about older people. Seeing an older person, young people feel respect, willingness to help and admiration.

- Most of the respondents have never witnessed direct marginalization or discrimination against the elderly.

- Most of the respondents have a positive or indifferent attitude towards the elderly.

- The correlation between the place of residence and the opinion about whether the elderly are needed by society has been shown. Compared to city residents, the vast majority of rural residents believe that the elderly are needed by society.

- It has been shown that women are much more afraid of their own old age than men.

- The analysis of the results did not reveal any relationship between gender and the ratio of old to young people, and vice versa.

- There was no correlation between the opinion on the incidence of the phenomenon of discrimination and marginalization and the gender of the respondents.

\section{References}

1. Robert D. Hill: Positive aging. Young at heart in the autumn of life. Laurum, Warszawa 2010, ISBN 9788362195541.

2. Fabiś A., Wawrzyniak J.K., Chabior A.: Human old age. Selected issues of social gerontology. „Impuls”, Kraków 2017, ISBN 9788380952621.

3. Rogala S.: Remember your old age. Higher School of Management and Administration in Opole. Opole 2011, ISBN 978-83-62683-15-4.

4. Rogala S.: Old age and it's social and family consequences. Higher School of Management and Administration in Opole. Opole 2013, ISBN 978-83-88980-95-4.

5. Dziuban A.: Social image of old and the perception of one's own body in the aging process. Literature review. Department of Sociology of Medicine, Department of Epidemiology and Preventive Medicine, Collegium Medicum of the Jagiellonian University. Gerontol. Pol. 2010; 18(3): 140-147.

6. Halicki J.: Images of old age drawn with the experiences of seniors. University of Bialystok. Białystok 2012, ISBN 978-83-7431-253-0.

7. Sutowicz A.M.: Intergenerational communication barriers against the background of cultural and social phenomena. Jan Kochanowski University, Kielce.

8. Tabuchi M., Nakaqawa T., Miura A., Gondo Y.: Generativity and Interaction Between the Old and Young: The Role of Perceived Respect and Perceived Rejection, Gerontologist. 2015, 55(4):537-47.

9. June A., Andreoletti C.: Participation in intergenerational service-learning benefits older adults: A brief report. Gerontol Geriatr Educ. 2018;2:1-6.

10. Czerwińska-Jasiewicz M.: Psychology of youth development in the context of the course of human life. Difin, Warszawa 2015, ISBN 9788379307135.

11. Magis-Weinberg L., Blakemore SJ., Dumontheil I.: Social and Nonsocial Relational Reasoning In Adolescence and Adulthood, J. Cogn. Neurosci. 2017;29(10):1739-1754. 